\title{
Alimentação do jundiá com dietas contendo óleos de arroz, canola ou soja
}

\author{
Feeding of jundiá with diets containing rice, canola or soybean oils
}

\author{
Marcos Eliseu Losekann' João Radünz Neto ${ }^{\text {II* }}{ }^{*}$ Tatiana Emanuelli"II \\ Fabio de Araújo Pedron ${ }^{\mathrm{I}}$ Rafael Lazzari ${ }^{I}$ Giovani Taffarel Bergamin ${ }^{\mathrm{I}}$ \\ Viviani Corrêia $^{\text {IV }}$ Ricardo Scherer Simões $^{\mathrm{V}}$
}

RESUMO

O objetivo deste trabalho foi avaliar a influência de óleos vegetais no desenvolvimento corporal e composição do filé de jundiás. Foram testadas seis dietas (32\%PB), sendo avaliados óleos de arroz, canola ou soja com 5 ou 10\% de inclusão, durante 90 dias. Os peixes (180, peso inicial $=71,0 \pm 0,8 \mathrm{~g}$ ) foram distribuídos ao acaso em 18 caixas (280L) de um sistema de recirculação de água, com temperatura controlada. Para avaliação de desempenho, estimaram-se variáveis como peso, comprimentos totais, padrão, altura caudal, sobrevivência, taxa de crescimento específico, fator de condição, consumo diário, conversão alimentar aparente e rendimento de partes comestíveis. Além disso, foram avaliadas a composição centesimal e taxas de deposição de proteína e gordura nos filés. Não houve diferenças entre os óleos e os níveis sobre o crescimento dos peixes; entretanto, os jundiás alimentados com $10 \%$ de óleo depositaram mais gordura no filé. Conclui-se que os óleos de canola, arroz e soja proporcionam bom crescimento e rendimento de partes comestíveis. As dietas contendo óleo de canola, com 5\% de inclusão, possibilitam menor deposição de gordura no filé.

Palavras-chave: óleos vegetais, jundiá, crescimento, composição do filé, Rhamdia quelen.

\section{ABSTRACT}

The influence of vegetable oils in the body development of jundiá (Rhamdia quelen) and its relationship with the flesh quality were evaluated in the present study. Six diets (32\% of crude protein) with rice, canola or soybean oil at 5 or $10 \%$ of inclusion were tested, for 90 days. The fishes $(180$, initial weight $=71 \pm 0.8 \mathrm{~g}$ ) were randomly distributed in 18 boxes (280L) in a water re-use system, with controlled temperature. The following parameters were considered for evaluation of fish performance: weight, total and standard length, survival, specific growth rate, condition factor, daily consumption, food conversion ratio, carcass and fillet yield, proximate composition and protein and fat deposition in the filets. There were no differences for the productive parameters among the tested treatments. Fishes fed with higher oil levels in the diets deposited larger fat percentage in the fillet. Canola, rice and soybean oils used as alternatives in diets in rearing of jundiá (Rhamdia quelen) provide good growth and carcass and fillet yield. Diets containing $5 \%$ of canola oil lead to a small fat deposition in the fillet of jundiás juveniles.

Key words: vegetable oils, jundiá, growth, fillet composition, Rhamdia quelen.

\section{INTRODUÇÃO}

O jundiá (Rhamdia quelen), é um peixe de água doce bastante apreciado para consumo humano na Argentina, no Brasil e no Uruguai e com mercado importante neste subcontinente (SALHI et al., 2004). É uma espécie rústica, de rápido crescimento, e que suporta baixas temperaturas, além de possuir hábito onívoro, que possibilita a utilização de diferentes ingredientes na sua alimentação (GOMES, et al., 2000; RADÜNZ NETO, 2004).

A importância dos lipídios na nutrição de peixes é bastante enfatizada e uma grande variedade de fontes de origem animal e vegetal são usadas na formulação de dietas. Os lipídios são utilizados como fonte de energia e ácidos graxos essenciais (AGE). Em

\footnotetext{
'Programa de Pós-graduação em Zootecnia (PPGZ), Universidade Federal de Santa Maria (UFSM), Santa Maria, RS, Brasil. IIDepartamento de Zootecnia, UFSM, 97105-900, Santa Maria, RS, Brasil. E-mail: jradunzneto@smail.ufsm.br. *Autor para correspondência. IIIDepartamento de Tecnologia e Ciência dos Alimentos, UFSM, Santa Maria, RS, Brasil.

${ }^{\text {Iv }}$ Curso de Zootecnia, UFSM, Santa Maria, RS, Brasil.

${ }^{\mathrm{v}}$ Curso de Medicina Veterinária, UFSM, Santa Maria, RS, Brasil.
} 
geral, se a dieta atende às exigências em AGE, o crescimento adequado do peixe é alcançado. Peixes de água doce como os surubins (Pseudoplatystoma corruscans) apresentam alta exigência de ácidos graxos poliinsaturados das séries ômega-6 e ômega-3 (MARTINO et al., 2002a).

A utilização de óleos vegetais em dietas para o jundiá é importante no crescimento e nas características de carcaça (MELO et al., 2002). Esses autores testaram o efeito da inclusão de 5\% de óleo de canola, óleo de fígado de bacalhau ou banha suína na dieta, sendo que o desempenho e o rendimento de carcaça (valores superiores a 80\%) dos jundiás não foram afetados pelas fontes de lipídios.

A qualidade da dieta, bem como as variações nos teores protéicos e lipídicos, influenciam na composição dos filés dos peixes (JUSTI et al., 2003). Logo, a utilização de óleos como fonte de lipídios possibilita diminuir a quantidade de proteína e o custo da ração, bem como fornecer um aporte de ácidos graxos essenciais necessários para o bom desenvolvimento dos peixes (MARTINO et al., 2002a).

Além disso, existe a necessidade de reduzir o uso de óleo de peixe nas rações, utilizando substitutos de origem vegetal. Estes ingredientes devem fornecer quantidade adequada de ácidos graxos poliinsaturados (ômega 3) no produto final para a alimentação humana (KAUSHIK, 2004).

Dessa forma, o objetivo deste trabalho foi verificar o crescimento, rendimento de partes comestíveis e composição química do filé de jundiás (Rhamdia quelen) alimentados com dietas contendo óleos de arroz, canola ou soja, em dois níveis de inclusão.

\section{MATERIAL E MÉTODOS}

O presente trabalho foi conduzido no Laboratório de Piscicultura da Universidade Federal de Santa Maria, no período de janeiro a abril de 2005. O experimento teve duração de 90 dias, utilizando-se um sistema de recirculação de água com 18 caixas de polipropileno (280L), com temperatura controlada e sistema de aeração tipo "Venturi” (RADÜNZ NETO et al., 1987). Foram utilizados 180 juvenis de jundiá (peso inicial: 71,0 $\pm 0,8 \mathrm{~g}$ ), oriundos do Setor de Piscicultura (UFSM), obtidos através de reprodução induzida e estocados na densidade de $2,5 \mathrm{~g} \mathrm{\textrm {L } ^ { - 1 }}$.

Testaram-se três óleos vegetais em dois níveis de inclusão (5 e 10\%), compondo seis dietas (com três repetições) em um arranjo fatorial (Tabela 1) com delineamento inteiramente ao acaso (DIC). Estas foram assim denominadas: OC5 (óleo de canola 5\%), OA5 (óleo de arroz 5\%), OS5 (óleo de soja 5\%), OC10 (óleo de canola 10\%), OA10 (óleo de arroz 10\%) e OS10 (óleo de soja 10\%).
Os peixes foram alimentados duas vezes ao dia (9 e 17h), até a saciedade aparente. Diariamente, foram aferidos os parâmetros físico-químicos da água do sistema de criação: temperatura $\left({ }^{\circ} \mathrm{C}\right)$, amônia total (ppm), nitrito (ppm), dureza total $\left(\mathrm{mgCaCO}_{3} \mathrm{~L}^{-1}\right)$, alcalinidade $\left(\mathrm{mgCaCO}_{3} \mathrm{~L}^{-1}\right)$, $\mathrm{pH}$ e oxigênio dissolvido (ppm). Exceto a temperatura, as demais análises foram realizadas através de kit colorimétrico (marca “Alfakit”).

Antes do início do experimento, dez peixes foram coletados aleatoriamente e abatidos por hipotermia para avaliação da composição centesimal inicial dos filés. Para a realização de análises da composição final (90 dias), utilizaram-se três peixes por unidade experimental (nove por tratamento).

Os parâmetros estimados foram: Comprimento total (CT): medida da porção anterior da cabeça até o final da nadadeira caudal, (cm); Comprimento padrão (CP): medida da porção anterior da cabeça até a inserção da nadadeira caudal, (cm); Altura caudal (AC): é a menor medida tomada na vertical no pedúnculo caudal; Peso (P): peso obtido ao final do experimento, (g); Sobrevivência (S), em \%; Taxa de crescimento específico (TCE): em \%/dia, segundo a fórmula: $\{[\ln ($ Peso Final $)-\ln ($ Peso Inicial) $] /$ (90 dias) $\}$ x 100; Fator de condição (FC): (Peso x 100) / (Comprimento total ${ }^{3}$ ); Rendimento de carcaça (RC): peso eviscerado, com as brânquias, expresso em \% do peso inteiro; Rendimento de filé (RFILÉ); Conversão alimentar aparente (CAA): alimento consumido / ganho em peso; Taxa de eficiência protéica (TEP): ganho em peso / quantidade de proteína consumida; Consumo diário (CD): Consumo no período/ [(peso final + peso inicial)/2] / dias x 100, expresso em \%PV/dia.

As cinzas e umidade do filé foram determinadas através da metodologia descrita nas Normas analíticas do INSTITUTO ADOLFO LUTZ (1985). A proteína foi determinada pelo método de KJELDAHL $(\mathrm{N}=6,25)$ e os lipídios através de extrator etéreo (AOAC, 1995). A partir da composição centesimal, foram calculadas (CAMARGO et al., 1999): proteína bruta total depositada no filé (PBTF); taxa de deposição de proteína bruta no filé (TPDF); gordura total depositada no filé (GTDF); taxa de deposição de gordura no filé (TDGF).

Os dados obtidos foram submetidos a testes de normalidade. Após isso, realizou-se análise de variância (2 vias: fontes X níveis), e as médias, quando significativas, foram comparadas pelo teste de DUNCAN $(\mathrm{P}<0,05)$. Utilizou-se para as análises o pacote estatístico “SAS” (1997).

\section{RESULTADOS E DISCUSSÃO}

Os parâmetros físico-químicos de qualidade de água aferidos foram: temperatura $\left(25,9 \pm 0,9^{\circ} \mathrm{C}\right)$, 
Tabela 1 - Composição das dietas experimentais (\%).

\begin{tabular}{|c|c|c|c|c|c|c|}
\hline \multirow{2}{*}{ Ingredientes } & \multicolumn{6}{|c|}{ Dietas } \\
\hline & OC5 ${ }^{1}$ & $\mathrm{OA} 5^{2}$ & OS5 ${ }^{3}$ & OC10 ${ }^{4}$ & OA10 ${ }^{5}$ & OS10 ${ }^{6}$ \\
\hline Farinha de carne e ossos & 30 & 30 & 30 & 30 & 30 & 30 \\
\hline Farelo de soja & 24 & 24 & 24 & 26 & 26 & 26 \\
\hline Milho & 20 & 20 & 20 & 20 & 20 & 20 \\
\hline Farelo trigo & 18 & 18 & 18 & 11 & 11 & 11 \\
\hline Óleo de canola & 5 & - & - & 10 & - & - \\
\hline Óleo de arroz & - & 5 & - & - & 10 & - \\
\hline Óleo de soja & - & - & 5 & - & - & 10 \\
\hline Sal comum & 1 & 1 & 1 & 1 & 1 & 1 \\
\hline Fosfato Bicálcico & 1 & 1 & 1 & 1 & 1 & 1 \\
\hline Mistura vitamínica e mineral $^{7}$ & 1 & 1 & 1 & 1 & 1 & 1 \\
\hline Etoxiquina $^{8}$ & 0,01 & 0,01 & 0,01 & 0,01 & 0,01 & 0,01 \\
\hline \multicolumn{7}{|l|}{ Composição centesimal (\%) } \\
\hline \multicolumn{7}{|l|}{ Nutrientes } \\
\hline Proteína bruta ${ }^{9}$ & 32,3 & 32,5 & 32,6 & 32,3 & 32,5 & 32,9 \\
\hline Energia digestível ${ }^{10}\left(\mathrm{kcal} \mathrm{kg}^{-1}\right)$ & 3123,8 & 3067,6 & 3157,9 & 3407,2 & 3454,7 & 3502,5 \\
\hline Matéria Mineral ${ }^{9}$ & 17,2 & 16,5 & 18,1 & 15,6 & 16,8 & 17,8 \\
\hline Extrato etéreo $^{9}$ & 11,8 & 11,6 & 11,9 & 15,2 & 17,0 & 17,4 \\
\hline Fibra bruta ${ }^{9}$ & 3,5 & 2,9 & 2,7 & 2,8 & 2,7 & 2,7 \\
\hline Umidade $^{9}$ & 9,5 & 8,6 & 8,5 & 7,7 & 10,2 & 8,7 \\
\hline Energia bruta ${ }^{9}\left(\mathrm{kcal} \mathrm{kg}^{-1}\right)$ & 4267 & 4422 & 4531 & 4558 & 4349 & 4624 \\
\hline
\end{tabular}

Dietas: ${ }^{1}$ OC5: óleo de canola 5\%; ${ }^{2} \mathrm{OA5}$ : óleo de arroz 5\%; ${ }^{3}$ OS5: óleo de soja 5\%; ${ }^{4}$ OC10: óleo de canola $10 \%$; ${ }^{5}$ OA10: óleo de arroz $10 \%$; ${ }^{6}$ OS: óleo de soja $10 \%$.

${ }^{7}$ Composição da mistura vitamínica e mineral (por kg de produto): Ác.Fólico: 400mg, Ác. Nicotínico: 14000mg, Ác. Pantotênico: 8000mg, Cobalto: 1500mg, Cobre: 15000mg, Colina: 1500mg, Ferro: 50000mg, Iodo: 700mg, Manganês: 23000mg, Selênio: 250mg, Vit.A: 6000000UI, Vit. B1: 1400mg, Vit. B2: 3375mg, Vit. B6: 4830mg, Vit. B12: 5000mcg, Vit. C: 25000mg, Vit. D3: 530000UI, Vit. E: 22500mg, Vit. K3: 5000mg, Zinco: 40000mg.

${ }^{8}$ (32\% etoxiquina, $18 \%$ propil-galato, $50 \%$ veículo-talco).

${ }^{9}$ Valores analisados.

${ }^{10}$ Calculado conforme Jobling (1995).

amônia total $(0,50 \pm 0,04 \mathrm{ppm})$, nitrito $(0,07 \pm 0,05 \mathrm{ppm})$, dureza $\left(45,19 \pm 11,34 \mathrm{mg} \mathrm{CaCO}_{3} \mathrm{~L}^{-1}\right)$, alcalinidade $\left(46,55 \pm 11,6 \mathrm{mg} \mathrm{CaCO}_{3} \mathrm{~L}^{-1}\right), \mathrm{pH}(7,01 \pm 0,49)$ e oxigênio

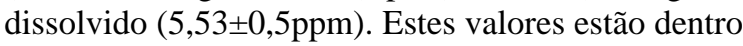
das condições adequadas para a criação da espécie (GOMES et al., 2000).

Os resultados de crescimento e sobrevivência obtidos (Tabela 2) não demonstraram efeito das fontes lipídicas e níveis de inclusão. Da mesma forma, diferenças no crescimento de jundiás alimentados com óleo de canola, de fígado de bacalhau e banha suína não foram observadas (MELO et al., 2002). A utilização de óleos (soja, milho ou linhaça) na alimentação do surubim (Pseudoplatystoma corruscans) também não proporciona diferenças no crescimento desta espécie (MARTINO et al., 2002a).

Os valores de peso ao final do experimento (90 dias) situaram-se em uma faixa de 151,0 a 159,1g, com TCE média de $0,8 \%$ dia $^{-1}$. Jundiás de igual classe de peso aos do presente trabalho criados no outonoinverno (temperatura média $18^{\circ} \mathrm{C}$ ) apresentam TCE de
0,63\% dia ${ }^{-1}$ (SOUZA et al., 2005). Juvenis de jundiá de menor tamanho (1-15g), alimentados com dietas práticas semelhantes às deste estudo, têm TCE de 3 a 4,9\% dia ${ }^{-1}$ (COLDEBELLA \& RADÜNZ NETO, 2002; LAZZARI et al., 2006). Estas diferenças de crescimento estão relacionadas a fatores como temperatura, tamanho corporal (menor tamanho: maior TCE) e composição da dieta (JOBLING, 1995; KAUSHIK, 1998).

Os valores de conversão alimentar $(1,3-1,5)$ dos juvenis de jundiá (Tabela 2) são semelhantes aos obtidos com juvenis de bagre americano (Ictalurus punctatus) alimentados com diferentes proporções de energia/proteína (REIS et al., 1989). Para espécies onívoras como o jundiá, esses valores de CAA são considerados satisfatórios. Um dos motivos da boa CAA obtida no experimento é a capacidade do jundiá de poupar proteína quando a concentração energética da dieta está adequada (MEYER \& FRACALOSSI, 2004).

O consumo de alimento dos peixes deste estudo $\left(1,4-1,5 \% \mathrm{PV} \mathrm{dia}^{-1}\right)$ é inferior ao relatado por 
Tabela 2 - Índices de desempenho dos jundiás aos 90 dias experimentais.

\begin{tabular}{|c|c|c|c|c|c|c|}
\hline \multirow{2}{*}{ Variáveis } & \multicolumn{3}{|c|}{ Fontes } & \multicolumn{2}{|c|}{ Níveis } & \multirow{2}{*}{$\mathrm{CV} \%$} \\
\hline & OC & OA & OS & $5 \%$ & $10 \%$ & \\
\hline$P(g)$ & 151,0 & 158,9 & 156,2 & 151,8 & 159,1 & 11,5 \\
\hline $\mathrm{CT}(\mathrm{cm})$ & 24,3 & 25,1 & 25,5 & 24,9 & 25,1 & 4,2 \\
\hline $\mathrm{CP}(\mathrm{cm})$ & 20,1 & 20,9 & 21,1 & 20,6 & 20,8 & 4,1 \\
\hline $\mathrm{AC}(\mathrm{cm})$ & 2,2 & 2,2 & 2,3 & 2,2 & 2,2 & 5,8 \\
\hline TCE $\left(\% \mathrm{dia}^{-1}\right)$ & 0,8 & 0,8 & 0,8 & 0,8 & 0,8 & 14,8 \\
\hline FC & 1,0 & 0,9 & 0,9 & 0,9 & 1,0 & 7,8 \\
\hline S (\%) & 88,6 & 100,0 & 93,3 & 92,2 & 95,5 & 12,8 \\
\hline RC (\%) & 86,0 & 84,9 & 85,9 & 85,8 & 85,4 & 4,2 \\
\hline RFILÉ (\%) & 32,5 & 32,4 & 33,2 & 32,8 & 32,7 & 6,8 \\
\hline RMAB (\%) & 8,2 & 8,0 & 7,9 & 8,1 & 8,0 & 7,6 \\
\hline CAA & 1,3 & 1,4 & 1,5 & 1,4 & 1,4 & 29,1 \\
\hline CD $\left(\% \mathrm{PV} \mathrm{dia}^{-1}\right)$ & 1,4 & 1,4 & 1,5 & 1,5 & 1,4 & 9,6 \\
\hline TEP & 3,0 & 3,2 & 3,1 & 3,0 & 3,2 & 21,2 \\
\hline
\end{tabular}

Médias obtidas não apresentaram diferença significativa $(\mathrm{P}>0,05)$.

Fontes: OC (óleo de canola); OA (óleo de arroz); OS (óleo de soja).

Variáveis: P: peso médio; CT: comprimento total; CP: comprimento padrão; AC: altura caudal; TCE: taxa de crescimento específico; FC: fator de condição; S: sobrevivência; RC: rendimento de carcaça (\%);

RFILÉ: rendimento do filé (\%); RMAB: rendimento do músculo abdominal (\%); CAA: conversão alimentar aparente; CD (\%PV/dia): consumo diário; TEP: taxa de eficiência protéica.

CV: coeficiente de variação.

LAZZARI et al. (2006), que encontraram valores entre 3 a 3,7\%. Estas diferenças podem ser atribuídas ao fato de os peixes encontrarem-se em diferentes fases de desenvolvimento. É importante destacar que não houve efeito dos níveis (5 ou 10\%) no consumo dos jundiás, visto que, para a maioria das espécies de peixe, a quantidade de lipídios da dieta afeta o consumo de alimento (HALVER, 2002).

Em relação ao rendimento de carcaça (RC), resultados semelhantes foram encontrados por MELO et al. (2002), quando testaram diferentes fontes de lipídios em rações para juvenis, e por LAZZARI et al. (2006), que testaram diferentes fontes protéicas na alimentação de juvenis de jundiá. Ambos obtiveram rendimentos variando entre 80 e $82 \%$. CARNEIRO et al. (2003), estudando o rendimento de carcaça de jundiás divididos em classes de peso, encontraram rendimento de $87,24 \%$ para animais que estiveram entre 201-300g de peso. Ainda, em análise comparativa, verificam-se rendimentos de $89,91 \%$ na carcaça do jundiá contra $89,67 \%$ para o bagre americano, não apresentando diferenças para as duas espécies (POUEY et al., 2005).

Os valores de rendimento de filé e músculo abdominal deste estudo são semelhantes aos do bagre africano (Clarias gariepinus), que, respectivamente, abrangem a faixa de 35,81 e 8,12\%, e o bagre americano (Ictalurus punctatus), cujos rendimentos são de 32,78 e 6,71\% (MARENGONI et al., 1998). Os valores de rendimento de cortes do jundiá em diferentes estudos demonstram que esta espécie, além de bom potencial de crescimento, proporciona quantidade satisfatória de carne tanto para venda inteira como processada (CARNEIRO et al., 2003).

Ao contrário do crescimento, ocorreu influência dos níveis e do tipo de óleo vegetal na composição química dos filés dos jundiás, notadamente quanto aos lipídios (Tabela 3). Os peixes alimentados com as dietas contendo óleo de soja (OS) depositaram $25,65 \%$ a mais de gordura em relação aos alimentados com óleo de arroz (OA) e 133,06\% superior aos tratamentos contendo óleo de canola (OC). Provavelmente, isto se deve à melhor relação entre ácidos graxos ômega 3/ômega 6 presentes no óleo de canola. As quantidades de proteína, umidade e cinzas não foram afetadas pelos níveis e fontes testadas.

Da mesma forma que foi observado nos filés dos jundiás neste trabalho, o aumento de níveis lipídicos em juvenis de surubim (Pseudoplatystoma corruscans) proporciona maior deposição (MARTINO et al., 2002b). Os lipídios se depositam no organismo na forma em que são ingeridos (saturados ou insaturados), também no fígado e vísceras, mas isto está atrelado às características metabólicas de cada espécie e à composição das fontes empregadas (XU et al., 2001).

A utilização de óleos vegetais geralmente não interfere no crescimento dos peixes; entretanto,

Ciência Rural, v.38, n.1, jan-fev, 2008. 
Tabela 3 - Composição centesimal (\%) e taxas de deposição de proteína e gordura nos filés dos jundiás ao final do experimento.

\begin{tabular}{|c|c|c|c|c|c|c|c|}
\hline \multirow{2}{*}{ Parâmetro } & \multirow{2}{*}{ Inicial } & \multicolumn{3}{|c|}{ Fonte } & \multicolumn{2}{|c|}{ Nível de inclusão } & \multirow[t]{2}{*}{ CV\% } \\
\hline & & $\mathrm{OC}$ & $\mathrm{OA}$ & OS & $5 \%$ & $10 \%$ & \\
\hline Umidade & 76,0 & 75,6 & 74,4 & 74,7 & 75,1 & 74,8 & 7,6 \\
\hline Proteína Bruta & 19,3 & 20,4 & 20,5 & 20,9 & 20,6 & 20,5 & 3,1 \\
\hline Lipídios & 5,1 & $4,7^{\mathrm{c}}$ & $6,5^{\mathrm{b}}$ & $7,4^{\mathrm{a}}$ & $5,1^{\mathrm{b}}$ & $7,0^{\mathrm{a}}$ & 6,2 \\
\hline Cinzas & 1,3 & 1,3 & 1,3 & 1,3 & 1,3 & 1,3 & 3,5 \\
\hline PBTF (g) & & 5,8 & 6,3 & 7,1 & 6,2 & 6,5 & 18,4 \\
\hline TDPF (mg dia-1) & & 65,3 & 70,1 & 79,2 & 69,8 & 73,3 & 18,4 \\
\hline GTDF (g) & & $1,2^{\mathrm{c}}$ & $2,3^{b}$ & $2,8^{\mathrm{a}}$ & $1,6^{\mathrm{b}}$ & $2,6^{\mathrm{a}}$ & 17,6 \\
\hline TDGF (mg dia ${ }^{-1}$ ) & & $13,8^{\mathrm{c}}$ & $25,5^{b}$ & $32,2^{\mathrm{a}}$ & $17,9^{\mathrm{b}}$ & $29,8^{\mathrm{a}}$ & 17,6 \\
\hline
\end{tabular}

Médias com letras diferentes, na linha, diferem estatisticamente pelo teste de Duncan $(\mathrm{P}<0,05)$.

Fontes: OC (óleo de canola); OA (óleo de arroz); OS (óleo de soja).

Variáveis: PBTF: proteína bruta total depositada no filé; TDPF: taxa de deposição de proteína no filé.

GTDF: gordura total depositada no filé; TDGF: taxa de deposição de gordura no filé.

CV:coeficiente de variação.

pode afetar a composição dos tecidos, o metabolismo de ácidos graxos e a aceitabilidade dos filés pelos consumidores (SARGENT et al., 1999; BELL et al., 2001). Semelhantemente ao verificado neste trabalho, GLENCROSS et al. (2003) verificaram que a inclusão de óleo de canola para o peixe marinho "Red seabream" (Pagrus auratus) diminui a quantidade de lipídios. Além disso, proporciona maior quantidade de ácidos graxos poliinsaturados e melhor aceitabilidade dos filés. Novos estudos deverão ser realizados para encontrar níveis ótimos de inclusão de óleos vegetais para o jundiá, associando a relação destas fontes com a composição em ácidos graxos essenciais (AGE) na carne e a digestibilidade destas fontes lipídicas, assuntos pouco explorados para esta espécie. Para o jundiá, estas são linhas de pesquisa que devem ser implementadas, pois de nada adianta o peixe ser eficiente na conversão do alimento se o produto final não for bem aceito pelo consumidor.

\section{CONCLUSÕES}

Os óleos de canola, arroz e soja utilizados na recria de jundiá (Rhamdia quelen), em 5 ou 10\% de inclusão, não afetam o crescimento e o rendimento de partes comestíveis. As dietas contendo óleo de canola, com nível de 5\% de inclusão, possibilitam menor deposição de gordura nos filés.

\section{AGRADECIMENTOS}

Ao Conselho Nacional de Desenvolvimento Científico e Tecnológico ( $\mathrm{CNPq})$, pelo fornecimento de bolsa de estudos ao primeiro autor e pela bolsa de produtividade em pesquisa ao professor João Radünz Neto. Aos graduandos, pósgraduandos e funcionários do Laboratório de Piscicultura da Universidade Federal de Santa Maria, pelo auxílio na preparação das instalações experimentais. À empresa Vitagri Nutrição Animal, pelo fornecimento de vitaminas e minerais para a elaboração das dietas.

\section{REFERÊNCIAS}

AOAC. (Association of Official Analytical Chemists). Official Methods of Analysis of AOAC. 16.ed. Arlington, Virginia, 1995. 1018p.

BELL, J.G. et al. Replacement of fish oil with rapeseed oil in diets of Atlantic salmon (Salmo salar) affects tissue lipid compositions and hepatocyte fatty acid metabolism. Journal of Nutrition, n.131, p.1535-1543, 2001.

CAMARGO, A.C.S. et al. Níveis de energia metabolizável para Tambaqui (Colossoma macropomum) dos 30 aos 180 gramas de peso vivo. 1. Composição das carcaças. Revista Brasileira de Zootecnia, v.27, n.3, p.409-415, 1999.

CARNEIRO, P.C.F. et al. Processamento: o jundiá como matéria-prima. Panorama da Aqüicultura, v.13, n.78, p.1721, 2003.

COLDEBELLA, I.; RADÜNZ NETO, J. Farelo de soja na alimentação de alevinos de jundiá (Rhamdia quelen). Ciência Rural, v.32, n.3, p.499-503, 2002.

GLENCROSS, B. et al. Evaluation of canola oils as alternative lipid resources in diets for juvenile red seabream, Pagrus auratus. Aquaculture Nutrition, v.9, p.305-315, 2003.

GOMES, L.C. et al. Biologia do jundiá Rhamdia quelen (Teleostei, Pimelodidae). Ciência Rural, v.30, n.1, p.179185,2000

HALVER, E.J. Fish nutrition. 3.ed. New York: Academic, 2002. 824p.

INSTITUTO ADOLFO LUTZ. Normas analíticas do Instituto Adolfo Lutz. V.I - Métodos químicos e físicos para análise de alimentos. São Paulo, 1985. 368p. 
JOBLING, M. Environmental biology of fishes. New York: Chapman \& Hall, 1995. 455p.

JUSTI, K.C. et al. The influence of feed supply time on the fatty acid profile of Nile tilapia (Oreochromis niloticus) fed on a diet enriched with n-3 fatty acids. Food Chemistry, v.80, p.489-493, 2003.

KAUSHIK, S.J. Nutritional bioenergetics and estimation of waste production in non-salmonids. Aquatic Living Resources, v.4, n.11, p.211-217, 1998.

KAUSHIK, S.J. Fish oil replacement in aquafeeds. Aqua Feeds: Formulation \& Beyond, v.I, n.I, p.3-6, 2004.

LAZZARI, R. et al. Diferentes fontes protéicas na alimentação do jundiá (Rhamdia quelen). Ciência Rural, v.36, n.1, p.240246, 2006.

MARENGONI, N.G. et al. Rendimento de filetagem de bagre africano Clarias gariepinus e bagre americano Ictalurus punctatus. In: REUNIÃO ESPECIAL DA SOCIEDADE BRASILEIRA PARA O PROGRESSO DA CIÊNCIA, 1998, Maringá, PR. Anais... São Paulo: SBPC, 1998. p.523-524.

MARTINO, R.C. et al. Performance and fatty acid composition of surubim (Pseudoplatystoma corruscans) fed diets with animal and plant lipids. Aquaculture, v.209, p.233-246, 2002a.

MARTINO, R.C. et al. Effect of dietary lipid level on nutritional performance of the surubim Pseudoplatystoma corruscans. Aquaculture, v.209, p.209-218, 2002b.

MELO, J.F.B. et al. Desenvolvimento e composição corporal de alevinos de jundiá (Rhamdia quelen) alimentados com dietas contendo diferentes fontes de lipídios. Ciência Rural, v.32, n.2, p.323-327, 2002.

MEYER, G.; FRACALOSSI, D.M. Protein requirement of jundia fingerlings, Rhamdia quelen, at two dietary energy concentrations. Aquaculture, v.240, p.331-343, 2004.
POUEY, J.L.O.F. et al. Rendimento de carcaça: análise comparativa entre jundiá e catfish. - A produção animal e o foco no agronegócio. In: REUNIÃO ANUAL DA SOCIEDADE BRASILEIRA DE ZOOTECNIA, 42., 2005, Goiânia, Go. Anais... Brasília: SBZ, 2005. CD-ROM.

RADÜNZ NETO, J. Manejo alimentar - nutrição. In: BALDISSEROTTO, B.; RADÜNZ NETO, J. Criação de jundiá. Santa Maria: UFSM, 2004. p.143-160.

RADÜNZ NETO, J. et al. Water re-use system of fingerling fishes in Brasil with emphasis on South american catfishes (Rhamdia quelen and R. sapo). Tropical Agriculture, v.64, p.2-6, 1987.

REIS, L.M. et al. Protein-to-energy ratios in production diets and growth feed conversion and body composition of channel catfish, Ictalurus punctatus. Aquaculture, Amsterdan, v.77, p.21-27, 1989.

SALHI, M. et al. Growth, feed utilization and body composition of black catfish, Rhamdia quelen, fry fed diets containing different protein and energy levels. Aquaculture, v.231, p.435444, 2004.

SARGENT, J.R. et al. Recent developments in the essential fatty acid nutrition of fish. Aquaculture, v.177, p.191-199, 1999.

SAS. Statistical Analisys System. User's Guide. Version 6.08, SAS INSTITUTE INC. 4.ed. North Caroline, SAS, 1997. 846p.

SOUZA, L.S. et al. Crescimento e sobrevivência do catfish de canal (Ictalurus punctatus) e jundiá (Rhamdia sp) no outonoinverno do Rio Grande do Sul. Ciência Rural, v.35, n.4, p.891-896, 2005.

XU, X.L. et al. Effects of dietary fat levels on growth, feed efficiency and biochemical compositions of Eurasian perch Perca fluviatilis. Aquaculture International, v.9, p.437449, 2001. 